\title{
EL CINE EN LAS REVISTAS LITERARIAS (PRIMER TERCIO DEL SIGLO XX)
}

\author{
CINEMA IN LITERARY JOURNALS \\ (FIRST THIRD OF THE TWENTIETH CENTURY)
}

\author{
Julia Sabina GutiérRez SÁncheZ \\ Universidad de Alcalá de Henares \\ juliasabina.gutierre@uah.es
}

Fecha de recepción: 27-04-2020

Fecha de aceptación: 21-05-2020

\section{RESUMEN}

Aunque en la actualidad hay numerosas publicaciones periódicas tanto nacionales como internacionales y sitios web en Internet dedicados al cine, a comienzos del siglo xx fueron las revistas literarias las principales tribunas del denominado «arte nuevo». Autores muy destacados como Alfonso Reyes, Federico de Onís, Ramón Gómez de la Serna, Antonio Espina, César Arconada, Benjamín Jarnés, Francisco Ayala, Rosa Chacel, Fernando Vela, etc., le dedicaron importantes artículos. En este trabajo analizamos cómo la cinematografía irrumpió en las revistas españolas de esos años y cómo evolucionaron las distintas perspectivas de un discurso, que sentaría algunas bases de lo que sería más adelante la crítica cinematográfica.

PALABRAS Claves: revistas; literatura; crítica; cine

\section{AbSTRACT}

Although numerous periodical publications and websites exist today, in Spain and abroad, at the beginning of the 20th century, literary magazines were the main forum for the so-called «new art». Very prominent authors such as Alfonso Reyes, Federico de Onís, Ramón Gómez de la Serna, Antonio Espina, César Arconada, Benjamín Jarnés, Francisco 
Ayala, Rosa Chacel or Fernando Vela dedicated important articles to cinema. In this work, we analyze how cinematography broke into the Spanish magazines of those years, causing the different perspectives of a discourse to evolve and laying the foundations for what Spanish film criticism would later become.

KEYWORDS: journals; literature; reviews; film

\section{EL CINEMATÓGRAFO, UN ARTEFACTO QUE FASCINA A LAS REVISTAS DEL INICIO DE SIGLO XX}

Desde su nacimiento en 1895, el arte cinematográfico es un misterio que no deja indiferente a los intelectuales. Antes de que aparecieran las grandes publicaciones dedicadas exclusivamente al cine, las revistas literarias de Francia, Italia o España aparecidas en las primeras décadas del siglo xx prestaron especial atención al fenómeno fílmico.

En Francia, en la revista Les Cahiers du mois, dirigida por François et André Berge colaboraron, entre otros, Louis Aragon, Marcel Arland, Henri Barbusse, André Breton, Jean Cassou, Blaise Cendrars, Charlie Chaplin, René Clair, Paul Claudel, Jean Cocteau, Jean Epstein, André Gide, James Joyce, Fernand Léger, André Maurois, Henry de Montherlant, Luigi Pirandello, Jean Prévost, Marcel Proust, Luigi Pirandello, Jean Prévost, Marcel Proust, Philippe Soupault, Jules Supervielle, Paul Valéry... que publican, además de textos sobre literatura, varios artículos sobre cine. En el número 16-17 de 1925, inserta la encuesta «Lettres, la pensée moderne et le cinema», en la que por primera vez se abordan las relaciones entre literatura y cine (AlBERSMEIER, 1978: 145163).

En Italia, entre los años 1926 y 1927, como ha explicado Aristarco (1966: 299-311), «las revistas de literatura como Convegno o Solaria incluyen en sus números ensayos sobre el fenómeno fílmico» (Gutiérrez Carbajo, 2019: 20).

En España, en La Gaceta Literaria, Revista de Occidente y España publican artículos de cine autores tan prestigiosos como Pío Baroja, Federico de Onís, Ramón Gómez de la Serna, Antonio Espina, César Arconada, Benjamín Jarnés, Francisco Ayala, Rosa Chacel, Fernando Vela, etc.

La revista España aparece en el año 1915, en la que colaboran los escritores más reconocidos de la época, como Valle-Inclán, Unamuno, Antonio Machado..., y en ella dedican artículos al séptimo arte, entre otros, Martín Luis Guzmán y Alfonso Reyes. Este último, según Fernández Cuenca (1960: 8-9) inaugura en Madrid la crítica europea de cine. Esta publicación y las revistas citadas, La Gaceta Literaria y Revista de Occidente, insertan numerosos artículos que van conformando una teoría de la estética fílmica.

Finalmente, Guillermo de Torre, fundador de La Gaceta Literaria (1927), con Ernesto Giménez Caballero y con frecuentes colaboraciones en Revista de Occidente, dedicó un importante apartado al cine en su obra Literaturas europeas de vanguardia (1925). 


\section{DE GALDÓS A ANTONIO ESPINA: LA CRÍTICA ANTE EL NUEVO ARTEFACTO CINEMATOGRÁFICO}

En Revista de Occidente publica Antonio Espina «Las dramáticas del momento» (1926) y «Reflexiones sobre cinematografía» (1927). En el primero de estos artículos se abordan las relaciones entre lo teatral y lo fílmico, a las que ya se había referido Pérez Galdós (El Liberal, 9 de junio de 1913), tranquilizando a aquellos que pensaban que el cine iba a acabar con el arte escénico. Más bien al contrario, el teatro, según el autor de Fortunata y Jacinta, potenciará todas sus potencialidades expresivas, gracias a la ayuda del fenómeno fílmico.

Pérez Galdós tiene como referente el cine mudo, y con la llegada del sonoro, el discurso fílmico añadirá al literario, como él mismo profetiza, una mayor emotividad. Así ha sucedido con sus textos literarios trasladados a la pantalla, como El Abuelo, Marianela, Fortunata y Jacinta, Tristana, Tormento, Nazarín y Doña Perfecta.

Pérez de Ayala en «De la pantalla y la escena» (1914) desarrolla la tesis de Pérez Galdós, y argumenta que el autor dramático de las primeras décadas del siglo xx no puede escribir una obra de teatro sin tener en cuenta que existe el cinematógrafo.

En este mismo contexto, Antonio Espina se pregunta: «¿Por qué experimentamos ahora como nunca la atracción del cine, la trascendencia del arte mudo?» (1926: 325). La respuesta la expone más claramente en otro artículo publicado en La Gaceta Literaria dos años más tarde, al que luego se aludirá, donde comenta que esa naturaleza del cine mudo a la que se refieren algunos conservadores del teatro, ha engendrado, según Espina, un procedimiento nuevo, gracias al cual nos entrarán los sonidos y la palabra a través de los ojos.

En «Las dramáticas del momento» insinúa ya estas observaciones, aunque se detiene especialmente en los aspectos pragmáticos, entre ellos, en el papel del espectador. A Antonio Espina no le interesa el público desde el punto de vista mercantil o comercial, como a algunos defensores de la crítica sociológica, sino desde la vertiente pragmática de la recepción, en la línea que mucho más tarde desarrollarían los teóricos de la estética de la recepción como Hans Robert Jauss, Wolfgang Iser y Harald Weiinrich o desde la perspectiva del receptor o el lector modelo de Umberto Eco.

En este sentido, Antonio Espina afirma que el público cinematográfico es todavía modesto y sentimental. Le entusiasman las películas «felizoides a la norteamericana», con conflictos de automóviles, hombres malos y pistolas, pero también actores apolíneos, risueños y atléticos y «vírgenes rubias del dólar y del sollozo» (EsPINA, 1926: 328). Un público, por cierto, con bastantes similitudes y con gustos parecidos al actual. Distingue, sin embargo, una doble clase de público: el «general y extenso del instinto y el particular y reducido de la inteligencia» (EsPINA, 1926: 328). En rigor para él, en España solo existe el primero.

En «Reflexiones sobre cinematografía», analiza la naturaleza, las formas y los diversos procedimientos del séptimo arte. Para Espina, en el espectáculo fílmico las manifestaciones externas, físicas y materiales destacan con más fuerza que las de carácter psicológico, que constituyen el verdadero fondo estético del nuevo arte. Se privilegian los componentes ma- 
teriales, representados por el mecanicismo y la pura tramoya, frente a la idea, a la fantasía y a la emoción. Esta preferencia de los elementos externos constituye, según Antonio Espina, una perversión de la técnica y de la ideología de la proyección, determinada por el desconocimiento de las «materias» psicológicas que se manejan, y que, aunque resulte complicado, son susceptibles de representación en la pantalla (GuTiÉrRez SÁnCHEZ, 2019: 105-120).

A estos aspectos se refiere Ramón Gómez de la Serna en varios de sus escritos y en revistas como La Gaceta Literaria. En el artículo «La nueva épica», (1928) publicado en esta revista, se refiere a procedimientos fílmicos, abordados desde otra perspectiva en la novela Cinelandia (1923) y que desarrollará más tarde en Ismos (1931).

Gómez de la Serna aborda, como Antonio Espina, el papel del público en el cine, y subraya la magnífica recepción que mereció esta manifestación artística, incluso en el caso de películas muy poco admirables. Considera que si en aquellos años hubiera existido un público exigente no habría podido encontrar filmes de gran calidad. Se prefieren asuntos lúdicos, porque el humorismo, rompiendo los movimientos y las épocas, rompe también los conceptos de espacio y de tiempo, y sabe buscar siempre un tiempo más libre y más listo. Argumenta que todavía no ha surgido un cine realizado por buenos artistas y escritores y se pregunta «por qué hemos de fiarnos de un arte en manos de tales 'escenaristas', tipos de otros oficios, señoritos de confuso destino, jugadores con ventaja que se han encargado de fraguar las películas. Gracias a que los «cameraman», con el potente y extenso procedimiento, han ido arreglando los argumentos» (Gómez DE LA SERNA, 1928: 4). Todo esto, sin embargo, está en vías de transformación, ya que llega el cine sonoro que va a poner las cosas en su sitio.

\section{LA INCORPORACIÓN DE LA PALABRA EN EL CINE Y LA CRÍTICA CINEMATOGRÁFICA}

Justamente un año antes de que Gómez de la Serna formulara esas reflexiones, concretamente el 6 de octubre de 1927, se había estrenado El cantor de jazz (The jazz Singer), considerada hasta ahora la primera película comercial del cine hablado. Decimos comercial porque existen descubrimientos recientes de experimentos que incorporaban el sonido a la imagen, como el descubrimiento por Agustín Tena de una cinta sonora en español protagonizada por Concha Piquer en 1923, que adelanta esta película en cuatro años a El cantor de jazz (The jazz Singer), rodada por Alan Crosland.

Este acontecimiento supondría un cambio radical en la concepción y en la práctica del cine, aunque continuaron realizándose películas mudas, porque muchos directores consideraban que esta era la verdadera naturaleza del séptimo arte, y que no necesitaba el instrumento del sonido.

Los historiadores subrayan el recurso del «blackface» en esta película, es decir, la presencia de intérpretes caucásicos. Se desconoce o se obvia la práctica de este recurso al criticar a Ramón, cuando se encargó de la presentación de la cinta en el CINECLUB que había instaurado en Madrid La Gaceta Literaria y apareció embadurnado de negro. El público 
español lo recibió con estruendosas carcajadas, absolutamente injustificadas, como se comenta en la revista Chaplin:

Ramón no se merece esto. Ramón no es un payaso. Su salida, disfrazado de negro de jazz, cae dentro del humorismo más puro, no en la vulgar e hilarante payasada, como creyeron los que, con sus carcajadas, querían dar la impresión de comprenderle, cuando lo único que demostraron fue su ignorancia y lo fuera de lugar que se encontraban al ser socios del cineclub. (1929: 1)

En «La nueva épica» Ramón explica que, con el cine hablado, vuelven a surgir los conflictos que se creían superados en la práctica de la representación y por otra parte se plantean nuevos problemas técnicos como la adquisición de costosísimos aparatos y la adecuación de las salas de exhibición, que mantenían las antiguas estructuras de los teatros. Para el autor, esto no arraiga nunca una novedad sin arruinar antes otros valores y otras posiciones estables, pero el reto merece la pena.

Y si Ricciotto Canudo observa que «el cine cierra el círculo en movimiento de la estética», de forma análoga se manifiesta Ramón en su trabajo «La nueva épica» en La Gaceta Literaria: «Con esos elementos grandiosos del cine que reúne lo distante y retrotrae lo pretérito, y unidos a la poesía y a la música, y a la novela y al drama, se podía crear algo que sobrepasara la ópera y que se podía llamar la nueva épica» (GómEZ DE LA SERNA, 1928: 4).

Considera muy positiva la incorporación en el cine de la palabra a la imagen, y afirma que esta situará a los personajes, y el ruido acompañará el silencio: «No veremos la detonación solo con humo, ni nada de eso será imitado por la orquesta como ha sucedido en la hibridez de algunos cines impacientes» (Gómez DE LA SERnA, 1928: 4). El cine hablado ayudará, además, a desvelar la diversidad de trucos a los que había tenido que recurrir el cine mudo.

Para Gómez de la Serna, el cine sonoro va a contribuir a otorgarle una verdadera dimensión a los textos literarios representando grandes obras, como las de Shakespeare. El dramaturgo inglés resultará más admirable en la pantalla, y cuando salgamos de ver esa película, que se representará con sus castillos y parajes verdaderos, nos encontraremos con que hemos asistido a un acto más verdadero que el de contemplar lejanas imágenes sueltas y menudas. Lo mismo piensa del teatro de Óscar Wilde y de su traslación a la pantalla. Alguna de sus obras como Una mujer sin importancia, modelo de diálogo, resultará ideal y justa en el cine sonoro.

Con el objetivo de resaltar los aspectos positivos del sonoro, se refiere a películas que fueron rodadas en la época del cine mudo, y señala lo que habrían ganado con este nuevo procedimiento. Analiza así el famoso film alemán Metrópolis (1927), del director vienes Fritz Lang, sobre una novela redactada por su mujer, Thea von Harbou, en el año 1926. Esta película, considerada una de las muestras más significativas del expresionismo alemán en las artes cinematográficas, se rodó todavía en la época del cine mudo, y podría haber resultado más comedida si se hubiese apoyado en la palabra, según Ramón.

El nuevo cine supone un avance fundamental porque las gentes que no saben leer ni escribir, saben oír. Nuestro autor está pensando no solo en el cine de ficción sino también en el de carácter documental: 
Se explicarán las visiones viajeras y los films científicos irán regados de explicaciones, y hasta asistiremos a la célebre operación, oyendo las palabras del cirujano inculcándonos así en la memoria lo visto de esa manera, que solo profundizan los ruidos diferentes de cada suceso, en este de la operación el de cristal (GÓMEZ DE LA SERNA, 1928: 4).

En la línea de la tesis expuesta por Pérez Galdós, el autor de Cinelandia está convencido de que si el cine mudo aportó grandes beneficios a la literatura lo mismo sucederá con el cine sonoro: «Alégrese de nuevo la literatura. Los escritores van a ser afortunados y van a viajar en trenes de película constantemente» (GómEZ DE LA SERNA, 1928: 4).

Por lo que se refiere al contexto europeo, en Italia, el citado Ricciotto Canudo fue un reconocido estudioso y crítico del séptimo arte. En los comienzos del siglo XX se traslada a París y se relaciona con círculos culturales y artísticos de la ciudad, especialmente con los estudiosos del fenómeno fílmico. En el año 1911 da a la imprenta su trabajo Manifiesto de las Siete Artes, en el que define el cine como un «arte plástico en movimiento», y lo califica como «séptimo arte» (URRUTiA, 1976: 38). En el 1921 funda con otros críticos el Club de los Amigos del $7^{\circ}$ Arte, que viene siendo considerado como «el primer cine-club de la historia». Una obra póstuma, La fábrica de las imágenes, reúne en 1927 algunos de sus textos más importantes.

Al igual que Ricciotto Canudo, el polaco Jean Epstein se traslada muy pronto a París, se relaciona con los primeros vanguardistas franceses y se convierte en otro de los grandes teóricos del cine. Funda la revista literaria Promenois y publica Bonjour, ;cinema!, en el que define el cine como «un arte inesperado, sencillamente, nuevo del todo». (DELEUze, 1984: 43, 69) Epstein se relaciona en París con André Breton y, sobre todo, con Luis Buñuel. Su obra más conocida es La chute de la maison Usher (1928). Como observa Gilles Deleuze su concepción del cine es la de un «arte propiamente visual (...) donde el movimiento puro se desprende unas veces de objetos deformados, por abstracción progresiva, y otras de elementos geométricos en transformación» (Deleuze, 1984: 43, 69). Epstein fue secretario de Augusto Lumière y un gran admirador del clásico Abel Gance.

\section{LA INDUSTRIA CINEMATOGRÁFICA Y LA CRÍTICA MILITANTE}

Como a Espina, a Ramón le interesan igualmente los aspectos pragmáticos, y analiza las competencias entre las producciones españolas y la industria extranjera. La industria de Hollywood favorecerá la condición de los actores y el cine hablado proporcionará justificación a lo que el instinto comercial y aduanero de Inglaterra había implantado sistemáticamente. Reitera su admiración por el fenómeno fílmico y lo considera incardinado en el contexto literario: «Por hoy, ahí va la prueba de mi admiración de siempre por el procedimiento cinematográfico, mi disconformidad por sus comedias anticuadas y mi fe en el cinematógrafo, reintegrado de lleno al arte y la literatura» (GómEZ DE LA SERNA, 1928: 4).

Una indudable dimensión internacional presenta una importante publicación sobre cine aparecida en París en el año 1923, que en la primera época llevaba el subtítulo de Cuadernos internacionales de valorización cinematográfica y en la segunda etapa el de Publica- 
ción internacional de valorización cinematográfica. Se trata de la prestigiosa revista Nuestro Cinema, bajo la dirección del citado Juan Piqueras.

En el número extraordinario de enero-febrero de 1933, César Arconada publica el interesante trabajo «Hacia un cinema proletario». Al comienzo de su artículo asegura que cada día son más los artistas que van hacia el proletariado con un certero instinto de augurio: «Los artistas tienen algo de ese instinto de lejanía y de fecundidad cálida que muestran las aves migratorias...marchan, huyen, se deslizan hacia el alto horizonte donde apunta un sol de esperanza. Este horizonte es el proletariado» (ARCONADA, 1933: 92).

Arconada plantea una cuestión, que estaba siendo objeto de ardorosos debates. Las discusiones sobre el arte proletario y la cultura proletaria surgen a raíz de la creación en Rusia en octubre de 1917 del Proletkult o «Asociación de cultura proletaria». En la Asociación se generaron múltiples controversias, discusiones y enfrentamientos, que han sido analizados con gran exhaustividad por la profesora Daniela Lucena (2008).

Arconada se hace eco de estos enfrentamientos y argumenta que pasar de la burguesía al proletariado no constituye para los artistas «un cómodo desplazamiento de viajante que muestra en uno o en otro lado el muestrario de sus mercancías» (ARCONADA, 1933: 92). Rechaza el esteticismo y el individualismo de artistas como Óscar Wilde, y asevera que el futuro del arte proletario del cine ha de nacer de los propios artistas, «de su colaboración, de sus facultades cultivadas en la lucha diarias y continua con el proletariado» (ARCONADA, 1993: 93).

En Rusia, el promotor principal del «Proletkult», Bogdanov, trazaba la difícil transición de la cultura burguesa a la cultura proletaria. En este contexto, no conviene obviar que el debate que se abre en 1920 sobre la organización de la cultura proletaria constituyó también una discusión entre los propios marxistas.

A Arconada, más que atender a este debate, le interesa analizar la necesaria evolución del «cine decadente» al revolucionario: «Lo que importa es que esta decadencia infecunda no se prolongue y que la revolución barra pronto este montón podrido de cosas» (ArcoNADA: 1993: 94). Sin obviar el componente político, los aspectos estéticos ocupan el artículo del mismo Arconada, «La poesía en el cinema», publicado en enero de 1935 también en la revista Nuestro cinema.

Comienza preguntándose de qué modo se representa en el cine «esa inundación de belleza que es la poesía» (ArConAdA, 1933: 94). Para Arconada, la poesía es el secreto que hace ascender la realidad vulgar de los hechos y de las cosas a la categoría superior de la belleza. Sentado este principio, asevera que si el cinema no tuviese relación con la poesía no sería arte. Sería un documento gráfico, una serie de hechos reales o imaginarios mecánicamente sucesivos, una representación o una transposición de la realidad, pero no una superación de la misma. Para Arconada, aquello que enaltece, que hace que adquiera belleza una serie de imágenes ordenadas es la poesía, solo es arte aquello que se define alcanzando un nivel poético.

En la base de la tesis de Arconada subyace la idea de que el cine y la poesía son procedimientos expresivos distintos con sistemas sígnicos diferentes, pero, como sostienen los teóricos de nuestros días, se producen intermediaciones o trasvases entre un sistema y otro. 
Arconada considera ejemplar el discurso poético y propone aplicar al cine alguno de sus procedimientos. En generosa reciprocidad el cine proporciona a la poesía y a la literatura en general muchos de sus temas y recursos. Algunas de estas teorías son desarrolladas y completadas por Vicente Huidobro y Guillermo de Torre:

Vicente Huidobro escribió en 1921 Cagliostro, novela fílmica sobre el tema de la nigromancia, que definió como un texto visual con una técnica influida por el cine. En ese mismo contexto vanguardista, Guillermo de Torre, además de su Friso Ultraísta. Film, de 1929, dedicó toda una sección a unos denominados "poemas fotogénicos», cuya dedicatoria a Jean Epstein, muestra una asimilación poco común de sus teorías cinematográficas. (GUTIÉRREZ CARBAJO, 2019: 21)

El profesor Agustín Sánchez Vidal, muy buen conocedor de la historia del cine y de los escritores de esta época, resalta con su sagacidad habitual la aportación del autor de las Literaturas europeas de vanguardia a esa rica investigación sobre el cine y su condición de adelantado en el reconocimiento de algunos creadores que acabarían convirtiéndose en clásicos:

Fue, además, uno de los primeros intelectuales españoles en apreciar el talento de Charles Chaplin y escribió en el número 33 de Cosmópolis (1921) artículos como «El cinema y la novísima literatura: sus conexiones» en el que «su percepción de las potencialidades simultaneístas, el cubismo, la segmentación de planos, la exaltación objetual y las metáforas visuales en concomitancia con la nueva poesía sólo serían superados por Buñuel con su artículo «Découpage e segmentación cinegráfica», publicado en La Gaceta Literaria mucho más tarde (en octubre de 1928), cuando ya había tomado contacto personal y profesional con Jean Epstein (SÁNCHEZ VIDAL, 1993: 133).

Aparecen, por tanto, referencias a algunos de los colaboradores de la revista francesa Les Cahiers du mois y a las publicaciones de directores españoles en las revistas literarias de la época (BuÑUeL, 1928: 1).

En los textos de los integrantes del 27, nacidos con el cine, es notable la influencia del séptimo arte, aunque muestran claramente sus preferencias por el cine extranjero frente al nacional. Francisco Ayala confiesa ante el cine su amor, encanto, sobrecogimiento y emociones que generarían algunas de sus obras.

En este clima, César Arconada se pregunta por qué no fundir la poesía con el cine, haciendo un cinema poético. Pone el ejemplo de Cocteau, otro de los colabores de Les Cahiers du mois, que, desde la poesía, va hacia todas las artes «como un peregrino con su fe» (ARCONADA, 1933: 94). No le resulta extraño que este creador, partiendo de su concepción poética, pretendiese llegar también al cinema como antes había llegado a las otras artes. Cocteau, en su Sang d'un poète quiso aplicar al cine la medida espacial que se aplica a la poesía y fracasó, según Arconada. Intentó hacer del cine, no ya un poema cinematográfico, que sí es posible, sino un poema poético, y el resultado no fue positivo.

En cambio, Arconada sí encuentra poesía en grandes filmes muy conseguidos, como en la Quimera del Oro o El circo de Chaplin. Magnífica poesía también la de la película Amanecer, probablemente la primera en la que se utilizan el ritmo y el matiz como procedimientos poéticos. Poesía humana, fuerte, «de gran ciudad y corazones abiertos» es la que inspiran 
Y el mundo marcha, Soledad, Suburbios...Poesía dramática, de contraste, halla en El último de los hombres, y poesía intensa, dinámica, subversiva, casi épica, hay en Soy un fugitivo.

Para Arconada, la más grande expresión poética conseguida en el cine está en El Acorazado Potemkin. Confiesa que no ha sentido nunca una emoción igual. Se trata de un momento de belleza no igualada, no superada, poéticamente perfecta. Es el tránsito maravilloso entre las escenas dramáticas, hirientes de gritos, aquellas escenas aceleradas y fuertes de la lucha, y la visión tranquila, enlutada de niebla y de crepúsculo, de la bahía, con la emocionada, larga fila de hombres que van al entierro de las víctimas.

Esta es, según Arconada, la poesía en el cinema y no puede ser otra. Esta que está dentro de su propia naturaleza, y es, no ya una desviación ni una adición, sino su propia esencia. La expresión, el lenguaje poético del cine puede estar en todo, en un ambiente, en una rápida imagen, en un gesto, en un ritmo, en un matiz, en un detalle. En definitiva, cuando una película sea una obra de arte es que está rebosante de poesía (ARCONADA, 1935: 2).

El tono político y militante de Arconada emerge de nuevo en el artículo «A propósito de una película nacional», publicado en el N. ${ }^{\circ} 16$ del año IV de la segunda época de Nuestro cinema. La película nacional es Sor Angélica dirigida por Francisco Gargallo en 1934 y producida por Selecciones Capitolio. La protagonista Carmela, tras ser abandonada por el padre de su hija, ingresa en una orden religiosa y deja a la niña con su familia. Esta cinta, que se consideraba perdida, ha sido recuperada recientemente por la Filmoteca Nacional en colaboración con la Filmoteca Portuguesa.

Arconada se propone en principio analizar el extraordinario éxito que tuvo la película, que lo atribuye a su carácter de folletín. Nuestro autor no acaba de entender la recepción que tuvo esta obra y se lamenta con estas palabras: «¡Pobre España ésta! ¿Dónde se ha visto algo parecido? ¿En qué país puede alcanzar una película folletinesca el rango de una auténtica resonancia nacional?» (ArConAdA, 1934: 47). Arconada da fe del éxito de «esta Sor Angélica de nuestras culpas» (Arconada, 1934: 47) que va por ciudades y lugares de España, conmoviendo por igual a los dignos jueces y a los honrados comerciantes, a las católicas señoritas como a las desenvueltas criadas, a las fuerzas vivas como a las fuerzas muertas. El defensor del «cine proletario» deja ver su componente clasista y antifeminista.

Cuando uno presencia en España sucesos nacionales de esta naturaleza no hay miedo de apartar el recuerdo de todos esos personajes de trueno y pesimismo que, según Arconada, España ha tenido en cada época y cita a Larra, a Costa, a Picavea y comenta: «CCuánta consecuencia hay en su consecuente existencia! ¡Voces en el desierto, sí, pero voces creadas por el propio desierto [...] España es, así, un saco baldío, un erial pedregoso!» (ARCONADA, 1934: 46).

En España según Arconada no hay más que dos actitudes: o la muerte o la rebelión: «En España todo lo que no sea rebelión, será muerte, será apelmazarse más (...) Que haya conservadores de la muerte, defensores de la infecundidad del pueblo, espíritu y tierras en baldío, solo se explica en aquellos que son líricos o que son propietarios» (ArConADA, 1934: 47). Arconada proclama que España necesita una revolución profunda, una tempestad que la cambie, que la desbroce y que la revuelva: «Mientras esto no se realice, será po- 
sible este absurdo y este mal gusto de que un folletín como Sor Angélica alcance un destino nacional» (ARCONADA, 1934: 47).

\section{LAS REVISTAS BUSCAN LA OPINIÓN DE LOS ESCRITORES ANTE ESTE NUEVO ARTE}

La Gaceta Literaria en su número 43, de 1 de octubre de 1928, que se abre con el artículo de Luis Buñuel sobre el «decoupage» o segmentación cinegráfica, como él la denomina, inserta una encuesta en la que se pregunta a los autores por la opinión que les merece el cinema desde el punto de vista literario.

Antonio Espina contesta que nuestros escritores teatrales lo consideran como un teatro imperfecto porque le falta la palabra. Se olvidan de las consideraciones comentadas de Pérez Galdós sobre el fenómeno fílmico solicitando la ayuda del cine para dar nuevo y hermoso medio de expresión al arte escénico.

Como se ha indicado con anterioridad, Espina observa que el cine ha engendrado nuevos y ricos procedimientos, que van a ser tremendamente rentables para los textos literarios: «En la gran cuartilla vertical, que es la pantalla hay cierto incierto pero enorme porvenir literario. A condición de escribir con chorros de luz en vez de hacerlo con gotas de estilográfica» (EsPINA, 128:6). En la pantalla se reflejan, según Espina, el paisaje de las desintegraciones, la integración de raros protagonismos: el protagonismo del subconsciente, el de la naturaleza inanimada, el del átomo acróbata, el del absurdo, el de la idea chófer. En la pantalla encontramos:

la vida sorprendida en sus más delicados resortes, por medio de la introscopia, la periscopia y la espectroscopia, combinadas. Nos hallamos en una épica soberbia que inaugura con la cineástica un orbe de sensaciones y descubrimientos. La cineástica será al siglo XX lo que la Imprenta fue al siglo XV. La Imprenta parió letras como la Matemática números.

(La Virgen parió a Jesucristo, como la Linterna a Charlot). (ESPINA, 1928: 6).

Para Benjamín Jarnés, las metáforas desechadas hace tiempo por el arte de escribir puede ahora utilizarlas el cinema. Pone el ejemplo de las películas Amanecer y Metrópolis y considera que el cine puede expresar el argumento, lo externo pero no los mecanismos interiores de los personajes. La literatura podrá cederle al séptimo arte el argumento de $E l$ rojo y el negro, pero no el estupendo mecanismo espiritual de Julián Sorel. Jarnés alude, sin embargo, al arte integral del cinema, y termina su artículo considerándolo «esperanza de auténticas alegrías en el antiguo recinto de las Musas» (JARNÉs, 1928: 6).

Para Concha Méndez las posibilidades que ofrece el cinema en el terreno artístico son incalculables. Piensa que las diversas manifestaciones culturales y artísticas difícilmente podrán alcanzar el lugar donde ha llegado el nuevo arte del cine (Méndez, 1928:6).

Según Francisco Ayala, el cine es la gran preocupación de los autores de su época, y anima al público a que asista a sus representaciones: «Prefiero recomendarles la asistencia al 
cine, que es el sacramento artístico de las multitudes nuevas, según mi punto de vista literario. Y según trato de mostrar en un próximo ensayo próximo a publicarse» (AYALA, 1928: 6).

En efecto, Ayala publicó su trabajo «El escritor y el cine», que ha sido recogido con posterioridad en Los ensayos. Teoría y Crítica Literaria (1972). En estos ensayos estudia, entre otros procedimientos cinematográficos, el efecto cómico del ralentí, mediante el cual, por ejemplo, «el atleta que salta pierde su peso y su fuerza; el bailarín se destrenza en una danza religiosa; el jinete alcanza un suelo transparente y milagroso» (AyALA, 1972: 454). Ilustra lo prodigioso de este procedimiento con una secuencia de Entr'acte de René Clair, en la que el director utiliza «las posibilidades cómicas del movimiento retardado al presentarnos -en un alarde subversivo- perspectivas imprevistas» (AyALA, 1972: 454). Entreacto (1924) es una película vanguardista de veinte minutos, sin argumento lineal, que mereció críticas muy diversas. En su estudio sobre El circo de Chaplin está ya aludiendo al papel que varias manifestaciones teatrales y algunos tipos como el clown desempeñan en el desarrollo del cine. Charlot, sucesor evolucionado de los grandes clowns ingleses, pasaría de la redondez del circo a actuar en el marco de una ventana, entre los cuatro ángulos de la pantalla.

El cine es algo muy complicado, según Miguel Pérez Ferrero, en el que «el snob, el minorista de selección fina y el participante del gran público libran batallas encarnizadas (aunque luego venga Charlot y a su modo los reconcilie)» (Pérez Ferrero, 1928: 6). Del mismo modo le parece que el escritor nuevo, de gran información y sensibilidad debe intervenir en cuestiones cinemáticas y el escritor viejo debe quedarse en los bastidores del teatro para engrosar las filas de los que en nuestro país impiden todo intento de renovación de la escena. Asimismo, opina que los cineastas españoles -exceptuando algún emigrado o algún posible incógnito- deberían comprender que su porvenir está en dedicarse a otra cosa (PÉREZ FERRERO, 1928: 6).

Esteban Salazar y Chapela, colaborador asiduo de diversos medios madrileños, como El Sol y La Voz, y de las revistas citadas que prestaron especial atención al cine, también contestó a la encuesta de La Gaceta Literaria sobre la concepción del cine desde el punto de vista literario. El cine es para él exposición perfecta de los valores físicos y vitales. Restitución del hombre al hombre, de la mujer a la mujer. Afirmación poderosa de la fuerza, del lujo, de la belleza del paisaje, de la tierra...El cine es la más formidable lección de cosas, el método y el procedimiento pedagógico magistral. El cine, su pantalla, vuelca en la sala en sombra de sus espectadores una lección cordial de vida, descorre en su cinta cuanto en el mundo es serio y codiciable. Es una sensación fenomenal de libertad, una explosión de las fuerzas elementales prístinas. La tempestad, el fuego, el mar, el odio, el amor... Si del teatro se ha dicho que es una casa a la que le falta una pared, del cine hay que decir más: es un mundo prieto e íntegro, al cual no le falta nada, ni paredes siquiera (SALAZAR Y Chapela, 1928: 6).

También publica encuestas sobre lo fílmico la revista Nuestro Cinema en las que se solicita la opinión a los autores literarios más importantes de la época. En la que inserta en el N. ${ }^{\circ}$ 17, Año IV, de la segunda época, contestan Francisco Ayala, Benjamín Jarnés, Federico García Lorca y Ramón J. Sender a las siguientes preguntas: 1) «¿Debe la censura española observar igual o distinta actitud ante el Cine Ruso que ante cualquiera otro cine extranjero?, 
2) ¿Considera el Cinema Soviético como un factor a tener presente en el desarrollo cinematográfico, artístico y cultural de España? 3) ¿Por su técnica o por su contenido?»

Benjamín Jarnés considera que solo debe existir la censura para el cinema cursi, acaramelado, blandengue, depresivo y estúpido que, según él, suele servirnos principalmente Norteamérica. El cine o es arte o no es nada, aunque dentro del arte, puede admitir algún contenido ideológico. Jarnés cree en el arte libre, y, dentro de esa libertad, piensa que el arte ruso es capaz de influir en el desarrollo general de la cultura de cualquier país. En España este cine puede influir por su técnica y por su contenido, siempre que se libere de toda angostura política y extienda su acción al mayor número posible de zonas de la humanidad.

Según Francisco Ayala, el cine ruso es expresión de un sistema de valores culturales de sentido muy peculiar. Su naturaleza artística se refleja en hechos políticos determinados -los del Estado Socialista- y en la medida en que este se aproxime o se aleje de la tonalidad dominante en el Estado español, la censura observará una u otra actitud frente al cine soviético. Personalmente, Ayala no quisiera ver la censura actuando sobre el cine ruso. Este cine, desde el punto de vista artístico, técnico y cultural significa una lección inapreciable y sería de gran provecho para el cine español.

Para Antonio Espina, no debe existir la censura ni para el cine, ni para el libro, ni para la prensa ni para el arte en general. Opina que el cine ruso tiene mucha labor que desarrollar en España. Esta labor debe ser infiltrante, estimulante, educadora hacia fuera y hacia dentro del estudio. Considera que hay que tener en cuenta el cine ruso tanto por su técnica como por su labor de propaganda social.

Federico García Lorca manifiesta contundentemente que «no debe censurarse el cine producido por la Unión Soviética, como tampoco debe prohibirse el cine de ningún otro país» (AyAla et al., 1935: 3). Si hemos aceptado y entendido la literatura de Dostoievski y Pushkin, con mayor razón debe tenerse presente el cinema soviético. El cine ruso, concluye García Lorca, debe tomarse como modelo, y esto es algo que los escritores y los críticos deben asimilar.

Ramón J. Sender, por último, argumenta que, de ser el Gobierno fiel a la Constitución de la República, no tiene más remedio que otorgar al cine soviético, a través de la censura, el mismo tratamiento que otorga al americano o al alemán. Un ejemplo de la asimilación del cine soviético en España, es, según Sender, la acogida que han tenido entre las masas películas como El expreso azul. La belleza de este film revolucionario ha entusiasmado a clases sociales muy diferentes. Las gentes reconocen en el cine soviético cualidades espaciales muy marcadas y más cerca de nuestra sensibilidad que las cualidades mejores del cine alemán o americano. Entre las mismas clases culturalmente más atrasadas -la alta burguesía religiosa, la aristocracia, etc.- el cine soviético es un mito tan importante artísticamente como era el arte escénico. Así como el teatro burgués español de las últimas generaciones se ha inspirado en el teatro inglés y francés, el cine español tendrá que orientarse por la espléndida tradición del cinema soviético. En el desarrollo del cine español ha de atenderse más a la técnica que al contenido del cine soviético, según Sender. 
En el mes de mayo de 1929 aparece en Madrid otra revista dedicada al cine, con el nombre de Juventud ${ }^{1}$. En la cabecera se explica que esta revista se remite a todas las empresas de exhibición y explotación de películas. En sus palabras de saludo se hace referencia a la naturaleza siempre dinámica del cine, que no está sujeta «a la rutina de un día igual a otro día», y ese dinamismo es el que quieren imprimir a la publicación.

Se trata de una publicación con intención de universalidad y una muestra de ello es la ilustración que insertan en la portada, con una fotografía del gran artista de la Paramount, Richard Dix, protagonista de la película Piel Roja.

En publicaciones no dedicadas específicamente al cine, como Plural y otras revistas de la vanguardia (OsunA, 2005), Benjamín Jarnés y otros autores escriben con frecuencia sobre el séptimo arte o insertan reseñas de libros de cine. Jarnés en el número que inaugura esta revista escribe una reseña de una obra de Ramón Gómez de la Serna, cuyo título alude a la meca del cine y ha llevado a algunos críticos a pensar que es fruto de su experiencia en Hollywood, cuando el autor de Cinelandia nunca estuvo allí. Califica la obra de Ramón de nueva guillotina donde será decapitada jovialmente la Retórica: «Esta nueva guillotina de Ramón se alza en una gran pista, no en un escenario. Anotemos la enorme diferencia del escenario a la pista. Arte de proscenio es arte de enfoques, de bambalinas, de dos dimensiones, donde todo puede fiarse a un plano» (JARNÉs, 1925:30).

Otra revista que le presta gran atención al cine es Nosotros. Semanario político de «Historia nueva», aparecida en Madrid en junio de 1930. En ella se publican varias reseñas de película, como la que escribe César Arconada sobre El batelero del Volga. Se trata de un tema ruso arreglado por el sentido industrial de las empresas yanquis y por el sentido social del mundo burgués. Rusia, según Arconada, no habría hecho esta película, con apariencia revolucionaria y con el fondo convencional bondadoso. En El batelero del Volga la doctrina es perfectamente ortodoxa y la moral es burguesa. Es el triunfo de lo individual y de lo particular frente a lo colectivo y lo social. La conculcación del código socialista. Pero, aparte de estos reparos, Arconada reconoce que la película está perfectamente realizada por Cecil B. de Mille, el cual ha querido incorporar influencias evidentes de la técnica rusa a la perfección de medios y a la abundancia de recurso de la técnica americana.

En esta misma revista escribe Arconada su crítica de la película Águilas, incardinada en el género de películas de guerra, focalizando en este caso la aviación. Las películas bélicas se han prodigado mucho, pero el asunto de la aviación, según nuestro autor, carece de recursos humanos, psicológicos y novelescos en esta cinta. La fábula nace ya ahogada, desprovista de vuelo, y de azar. Sin interés, sin expectación. Todo queda entonces limitado al interés puramente rival e informativo que presta la mecánica. Es una película patriótica, con alarde de fuerzas aéreas centrada en una nación que se resiste al imperialismo, pero a la que le falta arte y emoción.

Contrasta la valoración positiva que recibe el cine en estas revistas frente a la que merece para otras publicaciones como El Socialista y El Debate (de 1915 a 1918) (PELÁEz y

\footnotetext{
1 Se editaba en la calle Espronceda, número 4, de Madrid.
} 
Rueda 2010: 100) en las que, desde distintas posturas se defiende una ética menos transgresora.

Esta postura no muy favorable a los medios por parte de la crítica militante la encontraremos después en Horkheimer (1973: 123) para quien «los medios de comunicación altamente desarrollados sólo sirven para fortalecer las barreras que separan entre sí a los seres humanos [...] la radio y el cine no se quedan atrás en relación con los aviones y los cañones».

En las revistas citadas, especialmente en La Gaceta Literaria y en Revista de Occidente se incluyen análisis sobre el rodaje cinematográfico y sobre el guion, un elemento fílmico fundamental, pero «que todavía no ha sido reconocido y tiene una difícil inclusión en los géneros literarios» (GUTIÉRREZ SÁNCHEZ, 2018:28-29).

Finalmente, observamos cómo antes de que la crítica cinematográfica se centrase en el análisis particular de películas concretas, apuntó a cuestiones teóricas que luego serían retomadas a partir de los años sesenta y que igualmente interesarían a la teoría académica. Asuntos como la pragmática de la recepción, los diferentes tipos de público, el modo de representación hegemónico, la perspectiva militante de producción cinematográfica... eran cuestiones debatidas y argumentadas por teóricos y creadores de la época que no eran indiferentes ante un nuevo arte que cuestionaría las bases de la narrativa tal y como ellos la conocían.

\section{REFERENCIAS BIBLIOGRÁFICAS}

Albersmeier, Franz-Josef (I978): «Cinema: Langage et Littérature. Essai de Bibliographie», Cahiers du 20 e siécle, $\mathrm{n}^{\circ}$ 9, pp. 145- 163.

ArConada, CÉsAR (I933): «Hacia un cinema proletario», Nuestro Cinema, año II, No 8 y 9, pp. 92-93.

- (I934). «A propósito de una película nacional», Nuestro Cinema, año IV, nº 16, pp. 44-47.

- (I935). «La poesía en el cinema», Nuestro Cinema, $\mathrm{n}^{\circ} 1$ (segunda época), pp. 1-3.

- (1974). Tres cómicos del cine, ed. Marta Hernández, Madrid, Miguel Castellote.

Aristarco, Guido (1966): Novela y antinovela. El cine italiano después del neorrealismo, Buenos Aires, Jorge Álvarez.

Ayala, Francisco (I 928): «Encuesta a los escritores», LA GACETA LITERARIA, No ${ }^{\circ}$ 43, p.6.

- (I972): «El escritor y el cine», Los ensayos. Teoría y Crítica Literaria, Madrid, Aguilar, pp. 431538.

Ayala, Francisco, et AL. (1935). «Segunda encuesta», Nuestro Cinema, año IV, no 17 (segunda época), p. 3.

Brian Morris, Cyril (I993): La acogedora oscuridad: el cine y los escritores españoles (1920-1936), Códoba, Filmoteca de Andalucía.

BuÑUEL, LuIs (I928): «Decoupage o fragmentación cinegráfica», La Gaceta Literaria, año II, $\mathrm{N}^{\circ} 43$, p. 1.

Chaplin. Revista de Cinema, año I, no 1 (22 de febrero de 1929).

Deleuze, Gilles (1984): La imagen-movimiento, Barcelona, Paidós.

ECO, UMBerto ( I987): Lector in fabula, Barcelona, Lumen.

EsPina, ANTONio (I926): «Las dramáticas del momento», Revista de Occidente, año III, $\mathrm{N}^{\circ} \mathrm{xxx}$, pp. 316-329. 
- (1927): «Reflexiones sobre cinematografía», Revista de Occidente, año V, nº XLIII, pp. 36- 46.

- (1928). «Encuesta a los escritores», La Gaceta Literaria, n 43, pág. 6.

- Gómez De La Serna, Ramón (1923): Cinelandia, Valencia, Sempere.

- (1928): «La nueva épica», La Gaceta Literaria, n 44, p. 4.

- (1931): Ismos, Madrid, Editorial Biblioteca Nueva.

Gubern, Román (i999): Proyector De Luna: La Generación Del 27 Y El Cine, Barcelona, Anagrama.

Gutiérrez Carbajo, Francisco (20 I3): Teatro y cine: teorías y propuestas, Madrid, Ediciones Clásicas.

- (2019): Literatura y cine, Madrid, Universidad Nacional de Educación a Distancia (2a reimpresión).

Gutiérrez Sánchez, Julia Sabina (20 I 8): Rafael Azcona: el guionista como creador, introducción de Carlos Saura, prólogo de François Jost, Madrid, Lumière Pigmalión.

- (20I9): «ANTONio Espina y El CINE», REVISTA DE OCCIDENTE, No 457, pp.105-120.

Horkheimer, M. (1973): Teoría crítica, Barcelona, Barral.

Jarnés, Benjamín (i925): «Cinelandia, de Ramón Gómez de la Serna», Plural, n 1, pp. 30-31.

- (1928): «Encuesta a los escritores», La Gaceta Literaria, no 43, pág. 6.

LuCENA, DANiEla (2008): «Cultura proletaria y vanguardia rusa. Discusiones en torno a la construcción de un nuevo mundo», Questión. Revista Especializada en Periodismo y Comunicación, vol. I, $\mathrm{n}^{\circ}$ 12, https://perio.unlp.edu.ar/ojs/index.php/question/article/view/271.

MÉndez, Concha ( I928): «Encuesta a los escritores», La Gaceta Literaria, nº 43, pág. 6.

Morris, C. B. (1993): La acogedora oscuridad: el cine y los escritores españoles (1920-1936), Córdoba, Filmoteca de Andalucía.

Nieto Fernando, Jorge, y Asier Aranzubia (20I3): «Un idilio efímero o de cómo el influjo de la teoría renovó la crítica cinematográfica española en los años 70», Secuencias: Revista de historia del cine, $\mathrm{n}^{\mathrm{o}} 37$, pp. $62-82$

Osuna, RAFAel (2005): Revistas de la vanguardia española, Sevilla, Renacimiento.

Peláez, José, y José Carlos Vidal- Rueda (2002): Los públicos cinematográficos en el siglo XX, Madrid, Rialp.

PÉrez De Ayala, Ramón (i9i4): «Tabla rasa. De la pantalla a la escena», en Nuevo Mundo, año XXI, $n^{\circ} 1069$.

Pérez Ferrero, Miguel (i928): «Encuesta a los escritores», La Gaceta Literaria, Nº 43, pág. 6.

SÁnchez Vidal, Agustín (i993): «La generación del 27 y el cine», CuAdERnos HisPanOAmERICANOS, N ${ }^{\circ}$ 5I4-5I5, pp. 125-142.

Torre, Guillermo de (i925): Literaturas europeas de vanguardia, Madrid, Caro Raggio.

Urrutia, J. (1976): Contribuciones al análisis semiológico del film, Valencia, Fernando Torres Editor. 
